\section{Cleaning our seas and oceans of plastic litter}

Elise Blondel and Laura Klinkenberg

Allseas, Poortweg 12, The Netherlands

As a leading player in the global offshore market, Allseas is concerned about the future of our planet. Working every day at sea, we witness first-hand the devastating impact plastic pollution has on the world's oceans and marine life (see Figure 2). Plastic pollution is a global problem. We are committed to helping clean our oceans by developing systems to collect waste in rivers and waterways before it flows out to sea, where it spreads out, sinks, and breaks up into microplastics-affecting sea life and ultimately human health.

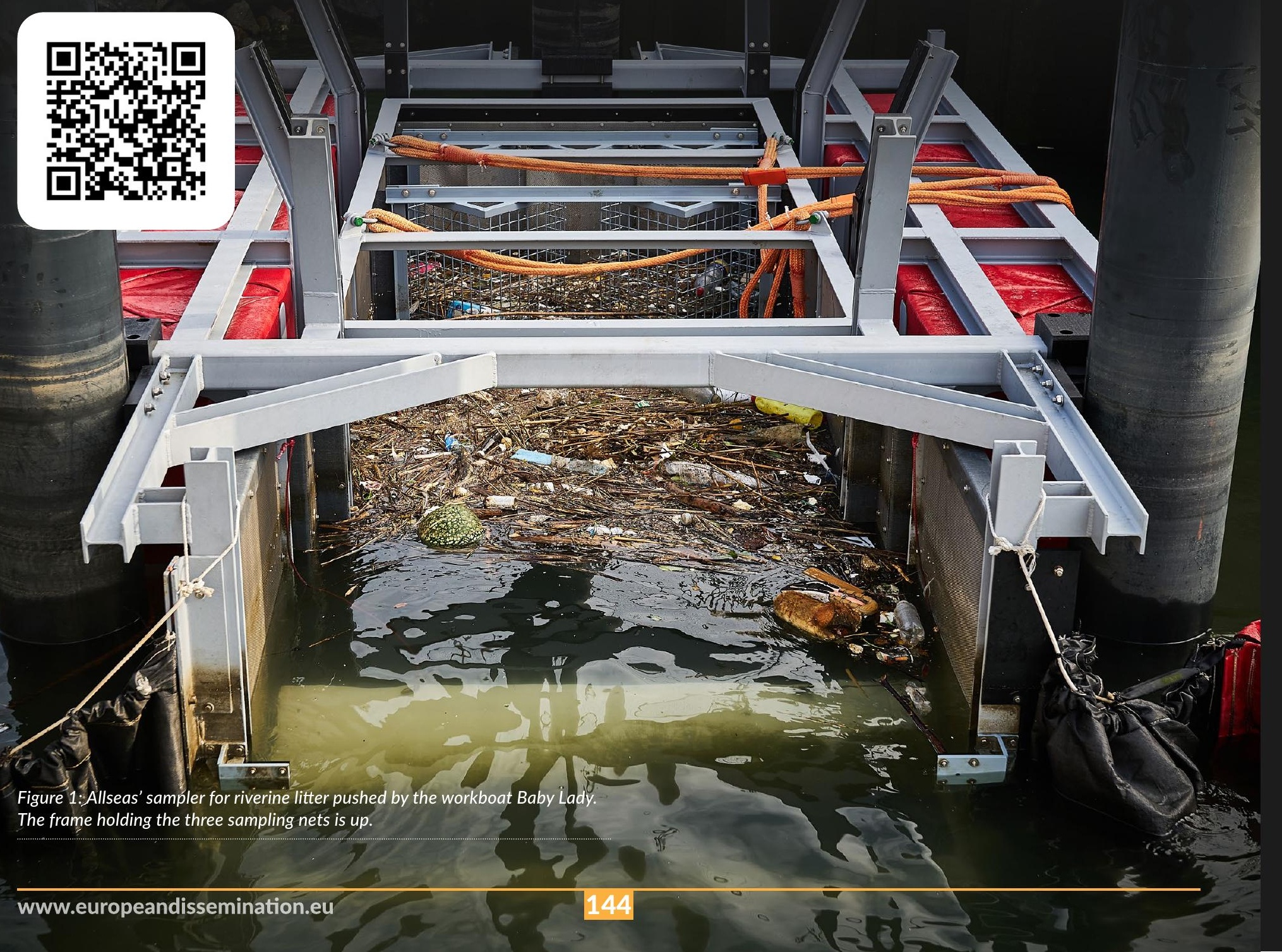

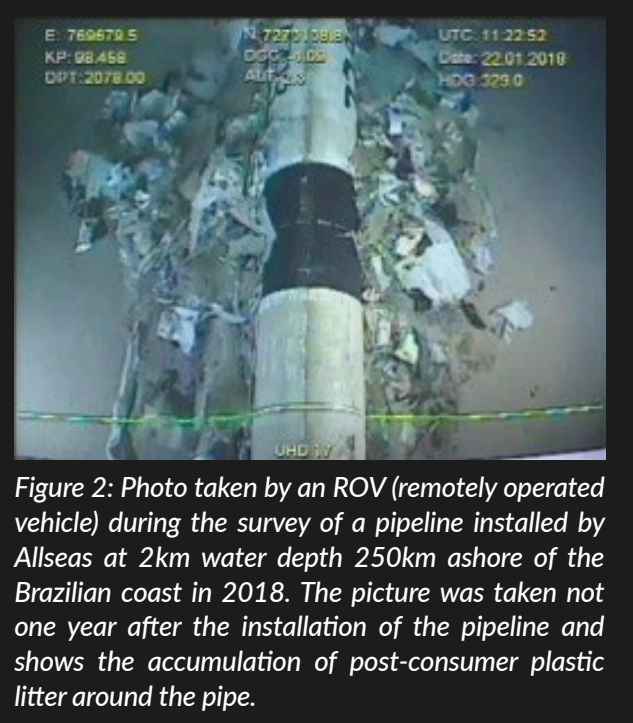

The plastic problem and how to solve it

Due to an expanding world population and the demand for ever-improving standard of living, plastic production has increased since 1950 to over 7,800 million tons with half of that plastic being produce between 2004 and 2017 (Schmaltz, 2020). Plastic has a lot of favourable properties that explain its prolific use; it is lightweight, strong, durable an resistant to corrosion. However, poor waste management has led to a build-up of plastic litter in the world's oceans. It is estimated that 150 million tons of plastic had already accumulated in the marine environment in 2016 (Schmaltz, 2020).

Most of the plastic pollution in the oceans has land-based sources and is transported through riverine systems. With the river plastics removal project launched in 2017, Allseas aims to tackle the problem close to the source. The strateg started with gaining more knowled and understanding of the problem researching the transportation of plastics in rivers via in-situ sampling and modelling, continuing with the successful installation and testing of two plastic collection system prototypes in 2019 and 2020.

The plastic pollution problem also needs to be addressed on a larger scale. Therefore, raising awareness throug media campaigns is also an essential part of Allseas plastic project. We also see changes in rules and regulations by the European Commission and other governing organisations to improve the way we handle plastics and decrease the inlet of plastic litter to the environment. One major issue is the ownership of the problem. Who takes ounership and responsibility? Creating ownership and responsibility among people and nations is one of the big challenges towards solving the plastic problem.

\section{LIFE SouPLess}

In 2018, Allseas' combined all its efforts to catch plastics in rivers into the LIFE SouPLess project, "Sustainable riverine PLastic removal and management." The driving goal of this project is a significant reduction of marine plastics, recovering them in rivers before they can spread to seas and oceans and thus protecting marine biodiversity, natural habitats and human helth. The project aims to install three systems to collect plastic litter in vious types of water environ has to redict hotspots of plastic accumulation in vers, and provide advice on sustainable nd cost-effective solutions for the postrocessing of the collected (plastic) litter. The project started in July 2018 and will in December 2022.

\section{Achievements to date}

- A full-scale plastic collection system has been designed, fabricated and installed in a non-tidal harbourthe Doeldok in the Port of Antwerp (Belgium). The system captures micro and macroplastics at the water surface and up to $1.5 \mathrm{~m}$ under the surface.

Afull-scale plastic collection system has been designed, fabrictiod ond installed in a tida harbour-the Viffsuizerhaven which is along the river Nieuwe Mas (n effluent of the Rhine river). The (an efllent of the Rhine rive). The of Rot Mas flows through the city Rotterdam (the Netherlands). - A numerical model has been developed
to calculate the transport of micro to calculate the transport of and macroplastics in rivers and accums. The model is applied to the river Nieuwe Maas, and trends have been validated with in-situ data from a sampling campaign in the river. - The basis of a methodological guide on riverine (plastic) waste management has been set up, containing the current technological options for postprocessing.

Engagement has taken place with national and international stakeholders such as authorities, post-processing companies, research institutes and NGOs.

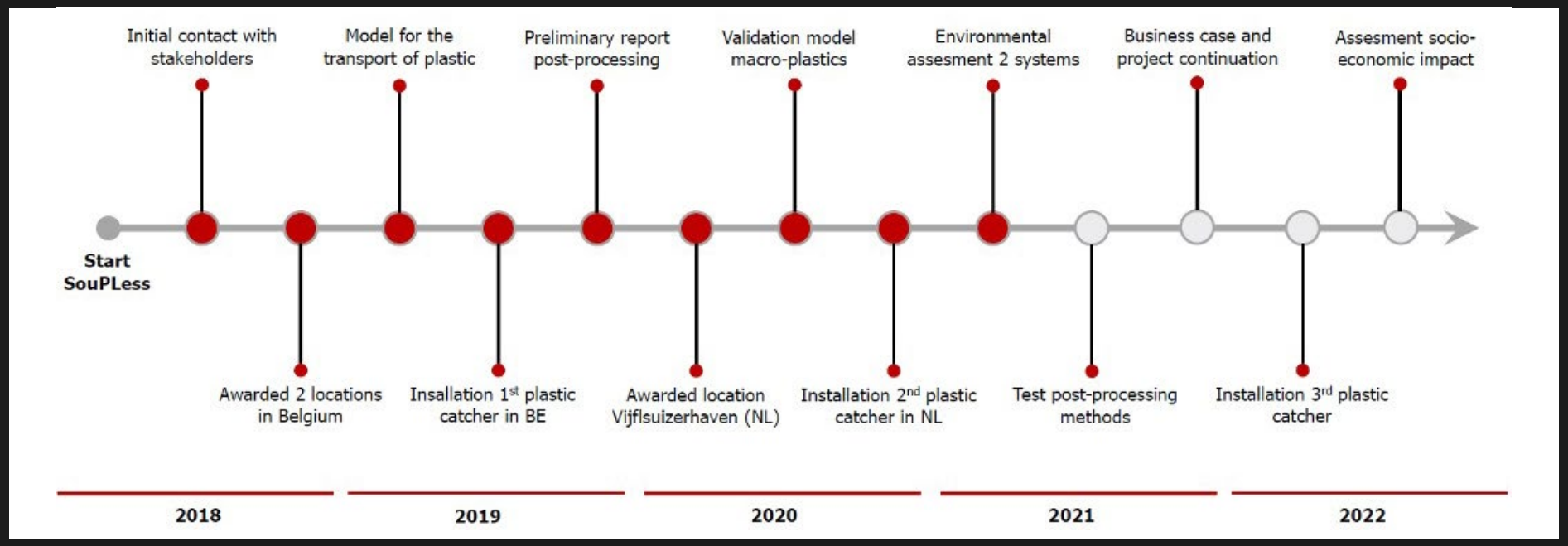


Currently, a third plastic catcher is in its desien phase. The full-scale collection system in a flowing hours of sampling liter 100 river. Furthermo, mechanical recyling and chemical recycling processes will be investigated using the litter collected by the plastic collection systems.

\section{A simulation model}

with Deltares

In the early stages of the project, Allseas collaborated with Deltares to develop a numerical model to simulate the transport of macro and microplastics in rivers (see Figure 3). The model's objective was to predict plastic hotspots, improve the efficiency of collection systems, find trends transport of plastic in rivers.

The model gave insight as to the best location for a plastic collection system. such as tidal zones and zones of high flux. It also showed that the whole water column should be targeted by a collection system, not only the water surface. Besides the
tides, wind also has a significant effect on the transport of plastics in surface water.

These trends were also found in data collected by in-situ measurements with

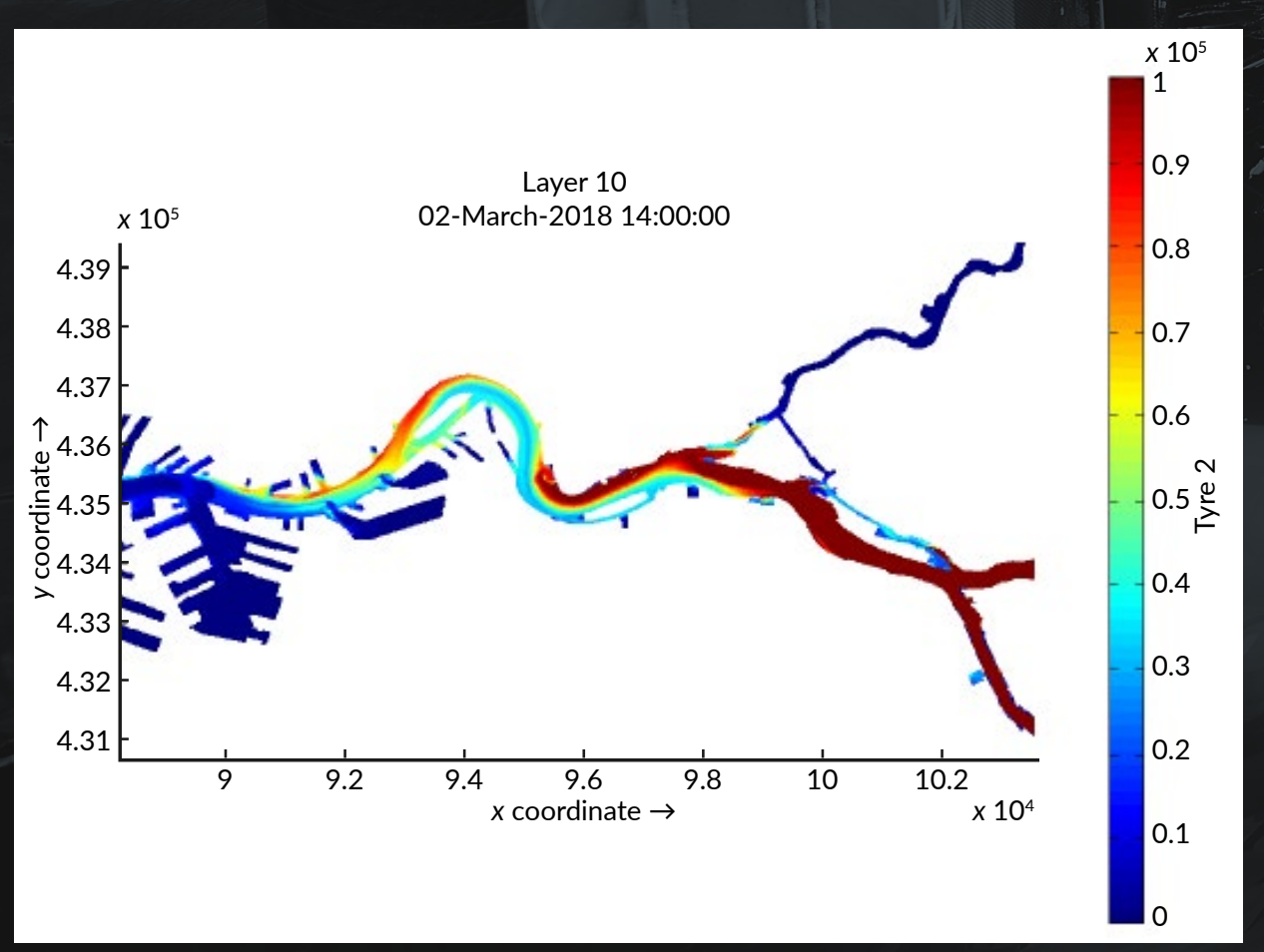

Figure 3: Example of the results obtained with the transport model for microplastics in the river Nieuw:
Maas. This figure shows the concentration of plastics under water in laver 10 of the simulation, which Maas. This higure shows the concentration of plastics under water in layer
means $10 \mathrm{~m}$ under water. the Doeldok in the Port of Antwerp in Belgium. It is a passive system, i.e. it does not reatre energy to function. $A 100 \mathrm{~m}$ fot theating boom guides the litter towards wind and wind diven curent (see Figure wind and whd-driven current (see Figure 5 and Figure 6). The boom is equipped with an underwater skit to convey both surface and underwater litter to the collection system.

The collection system is composed of a floating frame supporting two collection cages, one for large litter and one for smaller fiter (see figure 7 ). A system of filters enables the segregation of the litter by size and prevents the litter from escaping when the wind direction changes. An anti-retour flap closes when the wind drops or changes direction.

The cages have sidewalls made out of plastic mesh and can catch microplastics up to a size of $1 \mathrm{~mm}$. The Doeldok is a nontidal harbour, which allows the system to be moored at the quayside without moving. The system is emptied every

Plastic collection system for a three months by hoisting the cages out of the floating frame with a truck-mounted crane. This first prototype has been sold to the Port of Antwerp.

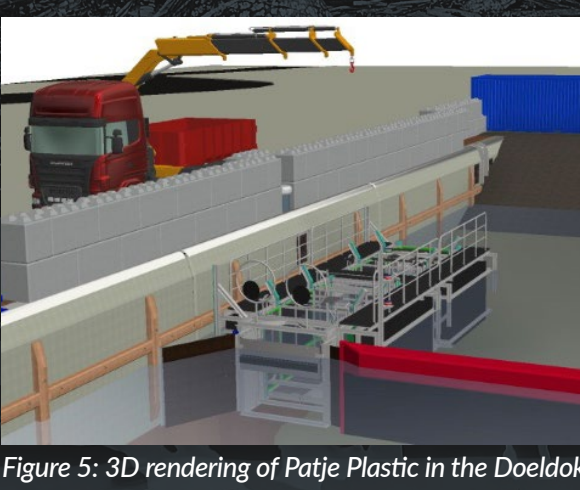

Figure 5: 3D rendering of Patje Plastic in the Doeldok. Aystem.

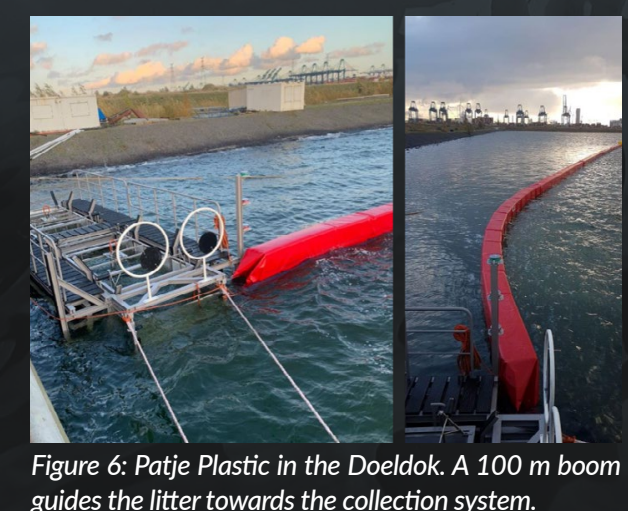

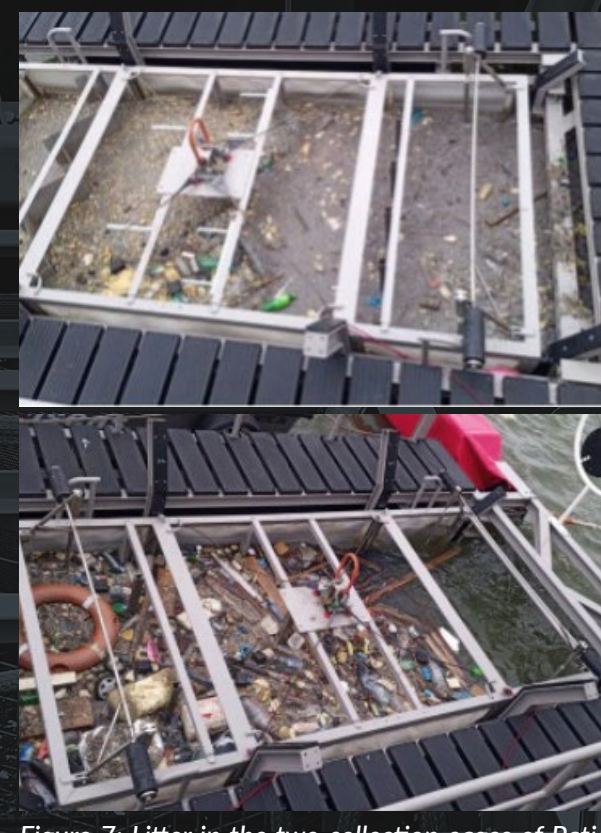

Figure 7: Litter in the two collection cages of Pate litter is in the back cage. The microplastics are clearly visible in the back cage (top).

\section{A plastic collection system} for a tidal harbour

In 2020, Allseas installed its second plastic collection system named "Catchy" as part of a pilot project with Rijkswaterstaat, the Dutch authority for public works and water management. This system is a passive system that catches litter flowing into the Vijfsluizerhaven, a creek along the river Nieuwe Maas in South Holland The river Nieuwe Maas is an effluent of the Rhine that flows through the city Rotterdam and the port of Rotterdam.

Two floating booms of $200 \mathrm{~m}$ and $12 \mathrm{~m}$ equipped with an underwater skirt guide the floating and underwater litter towards a collection system under the action of wind and current. The collection system is composed of a floating frame supporting a collection cage. It is moored to spud piles to move vertically with tidal variations of the water level. An antiretour flap and a system of filters prevent litter from flowing out of the system with unfavourable wind and/or current.

The system captures macro and microplastics up to $3 \mathrm{~mm}$. It is emptied once a month with a mobile crane. The litter is further sorted and analysed into different size categories and materia categories. This analysis is an important part of the project with Rijkswaterstaat to get insight into the types and amounts of litter, the possible sources of the litter, and how it can be postDrocesed with existing technologies. The Dutch government can further use this information to take new measures in tackling plastic pollution in rivers.
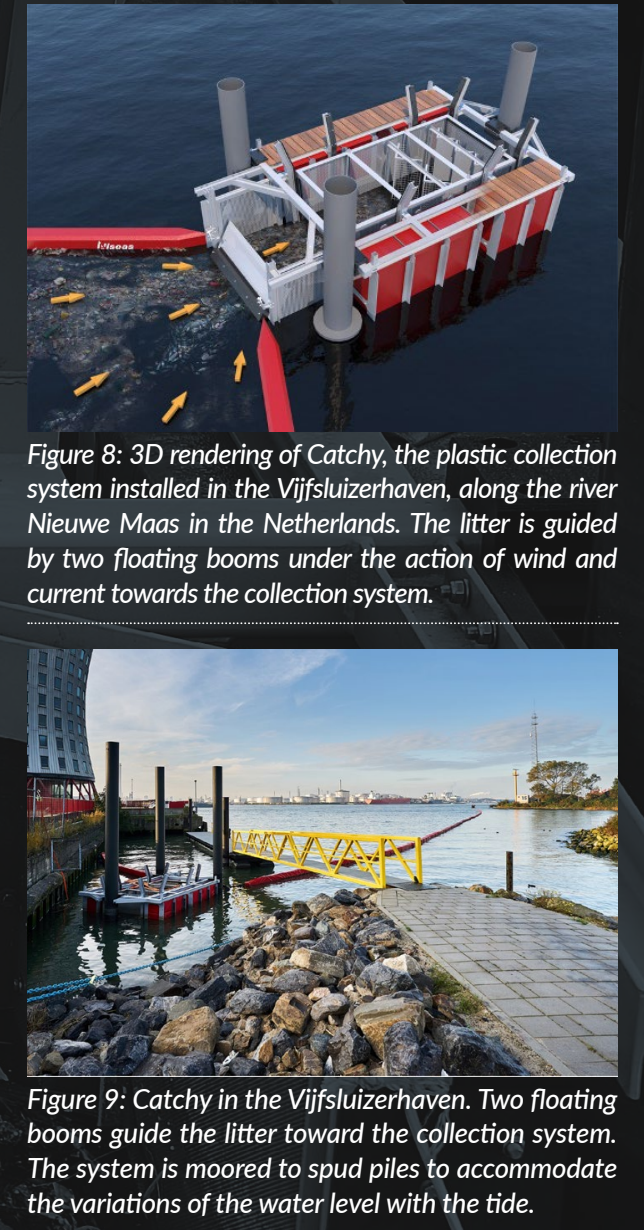

A plastic collection system for a flowing river

Alseas is currently designing a third plastic collection system, this time for use in flowing tidal and non-tidal rivers. It will, therefore, need to withstand the strong system is due to be installed and tested in a Dutch river in 2021/2022

At a later stage, the aim is to install the system in highly polluted rivers in developing countries like India and Thailand. A new method that allows continuous emptying will therefore be tested. As with the previous systems, it will be a passive system collecting micro and macroplastics.
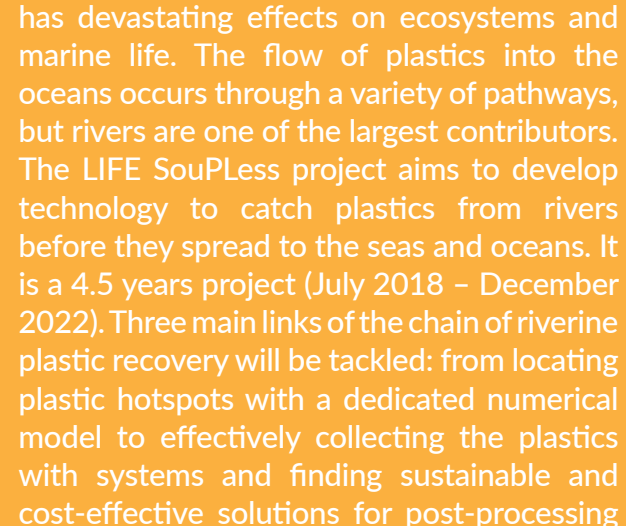

cost-effective solution
the collected litter.

PROJECT LEAD
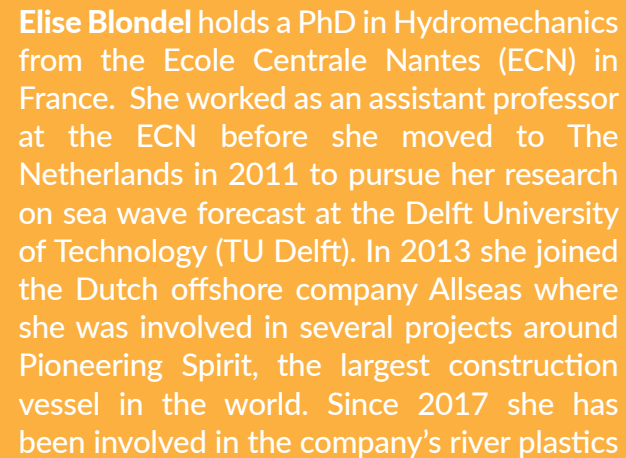

\section{CONTACT DETALLS}

Elise Blondel
Poortweg 12,2612 PA Delft
The Netherlands

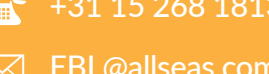

Ditt

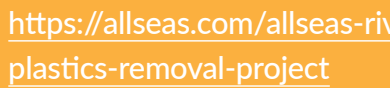

